\title{
Sensory Freshness Assessment of Ice Stored Rainbow Trout (Oncorhynchus mykiss)
}

\author{
Fazli Shabani ${ }^{1, \mathrm{a}}$, Elvira Beli ${ }^{2, \mathrm{~b}}$, Agim Rexhepi ${ }^{1, \mathrm{c}, *}$ \\ ${ }^{1}$ Faculty of Agriculture and Veterinary of Pristina, Kosovo, \\ ${ }^{2}$ Department of Animal Production Agriculture University of Tirana, Albania \\ *Corresponding author
}

\begin{tabular}{|c|c|}
\hline A R T ICLE INFO & A B S T R A C T \\
\hline $\begin{array}{l}\text { Keywords: } \\
\text { Ice storage } \\
\text { Quality Index Method } \\
\text { Rainbow trout }\end{array}$ & $\begin{array}{l}\text { Sensory quality characteristics of fish are very important factors on acceptance and market value of } \\
\text { the product. Quality assessment of fish should be precise, fast, systematic and comprehensive } \\
\text { regarding freshness attributes. The objectives of this study were to describe weather the QIM } \\
\text { (Quality Index Method) scheme for salmonides can be used to determine the freshness and describe } \\
\text { the sensory changes during storage. Quality assessment of the fresh water rainbow trout (n=36) was } \\
\text { performed on day } 1,7,14 \text { and } 21 \text { of ice storage on temperatures from } 0.6-0.8^{\circ} \mathrm{C} \text {. Through the QIM } \\
\text { scheme the specific freshness attribute deterioration can be very well described and the QIM score } \\
\text { produced a clear result, which showed that the deterioration of fish is linear and has a strong } \\
\text { correlation with the time of storage. The QIM scheme for farmed salmon can be used to evaluate the } \\
\text { freshness of the rainbow trout. It can also be used to ascertain and predict the remaining shelf life of } \\
\text { rainbow trout stored in ice. Under similar conditions, the maximal shelf life of ungutted rainbow } \\
\text { trout is } 14 \pm 2 \text { days or } 15 \text { demerit points of framed salmon QIM scheme. }\end{array}$ \\
\hline
\end{tabular}

Shefry quality

Shelf life

\section{Introduction}

Determination of food freshness is an important issue all around the world. Rapid and accurate determination of product freshness is necessary to follow the rate of business and market development. This is especially important for fish and other seafood, because of their short shelf life and the fact that freshness is one of the most important factors of fish and seafood quality (Bonilla et al., 2007; Sveinsdottir et al., 2002). A method that enables fast and accurate freshness determination is Quality Index Method (QIM). This method firstly was developed by Tasmanian Food Research Unit (Bremner, 1985) and is now vastly used. QIM (Quality Index Method) is a sensory based method for freshness assessment of fish and see food products.

Sensory methods are important and were commonly used to assess the freshness of the fish and seafood in general, but they were considered that do provide only a subjective assessment. Today the QIM have turned sensory evaluation to an objective tool (Vaz-Pires and Seixas, 2006; Hyldig and Green-Petersen, 2004) by which sensory freshness assessment is performed in a systematic and documented way.

On a QIM scheme (Table 1), the specific freshness attributes are listed, and they must be evaluated and estimated one by one, by a score system from 0-2 or 0-3 demerit points, where 0 is for fresh and 3 for spoiled fish. The score of each attribute has to be collected to give an overall score, the so-called QI (Quality Index).

Today the QIM is considered as a practical, objective and easy tool to evaluate fish freshness and is now being used more in science, production, market and official seafood inspection. Other than the freshness assessment, the QIM can also be used to predict the remaining shelf life of ice stored fish (Hylding and Green-Petersen, 2004; Sveinsdottir et al., 2003).

Today, at least 34 publications for specific seafood species or products exist. The QIM is available in 11 languages (English, Dutch, German, Icelandic, Danish, Italian, Norwegian, Spanish, Portuguese, Greek and French) and the QIM schemes are available for 13 fish 
species; brill (Rhombus laevis), cod (Gadus morhua), deep water shrimp (Pandalus borealis), farmed salmon (Salmo salar), whole fjord shrimp (Pandalus borealis) haddock (Melanogrammus aeglefinus), herring (Clupea harengus), peeled shrimp (Pandalus borealis) plaice (Pleuronectus platessa), pollock (Pollachius virens), redfish (Sebastes mentella/marinus), sole (Solea vulgaris) and turbot (Scophthalmus maximus), (www.qim-eurofish.com).

It is well known that seafood, especially fish, have unique characteristics, as result, type-specific QIM scheme were developed and designed from fisheries, researchers and institutions to describe and summarize all these characteristics during assessment. Nowadays exist some publications on rainbow trout freshness assessment with QIM and was attempted to establish (Wunnenberg and Oehlenschlag, 2008) or modify (Ozogul et al., 2017; Öz et al., 2017; Öz, 2018) a current scheme, but until now none of them are accepted as an official form by the "QIM Eurofish Alliance" and it is not included in the QIM scheme for rainbow trout in the QIM manual.

Because of this, in this study, the QIM scheme for farmed salmon was chosen and used to evaluate the changes in rainbow trout, because of their similarity and the fact that both species belong to the same family (Salmonides).

The objectives of this study were to determine whether the QIM for farmed salmon can be used to assess the freshness, describe the sensory changes, ascertain and through it to predict the shelf life of the ice stored rainbow trout.

\section{Material and methods}

\section{Materials}

Freshwater rainbow trout with an average round weight of $314 \pm 49 \mathrm{gr}$ and fork length of $30 \pm 1.5 \mathrm{~cm}(\mathrm{nr}=36)$ were sampled in September 2014 at "Trofta Istog" fish farm in Kosovo. The fish were farmed for about 15 months in concrete raceways using the EFICO Vital 808 feed from BioMar AS (Brande, Denmark). The gross composition of the feed was: crude protein $42 \%$, crude lipids $24 \%$, nitrogen free extract $17.4 \%$, crude cellulose $2.5 \%$, ash $9.4 \%$, total phosphorus $1.3 \%$, as well as vitamins (A, C, D3 and $\mathrm{E})$. The fish were fasted for 8 days before the experiment started (day 1). Just before sampling of the fish at the farm, the levels of dissolved oxygen, acidity and temperature in the raceway were $79 \%$ saturation, $\mathrm{pH} 7.80$ and $10.9^{\circ} \mathrm{C}$, respectively. These fish were taken one-byone from the raceway and were rapidly killed by a sharp blow to the head. Fish were washed externally in tap water before they were put whole in styrofoam boxes filled with ice (not gutted). All boxes of iced fish were then transported to the University of Prishtina for quality assessment. Indices of fish quality were assessed on Day 1, 7, 14 and 21 post mortem. Crushed ice was replenished whenever needed. In accordance with commercial processing routines, none of the fish in this study were bled.

\section{Methods}

The Quality Index Method is a scheme for evaluating fish freshness by sensory attributes (Hylding and GreenPetersen, 2004). As described for Atlantic salmon by Sveinsdottir et al, 2002) Demerit points (0-2 or 0-3) are given to each of the following attributes: skin (colour/appearance, mucus, odour and texture), eyes (pupils and form), gills (colour/appearance, mucus and odour), and abdomen (blood in abdomen and odour). By adding the points from all attributes, the total score (QI value) ranges from 0 (very fresh fish) to 24 (spoiled fish) Table 1.

The fish were assessed from a group of 5 panellists. Panellist were trained before in 4 controlled experiments with 9 fish for each panellist on every training section.

\section{Statistics}

The collected data of the different variables were first tested for normality and homogeneity of variance by using the Shapiro-Wilk and Levene Median tests, respectively. If the tests passed, Student t-tests were run. Otherwise, Mann-Whitney Rank Sum tests were used to test significance $(\mathrm{P}<0.05)$. For the storage experiment, the effect of storage time (Day 1, 7, 14 and 21) was tested using a one-way ANOVA followed by a Holm-Sidak post hoc test when significance was indicated. If normality or homogeneity of variance tests failed, the Kruskal-Wallis One Way Analysis of Variance on Ranks method was applied followed by a Tukey or Student-Newman-Keuls post hoc test.

\section{Results and discussion}

The total QI score of the not gutted rainbow trout during 21 days of ice storage are shown in Figure 1.

The QIM produced a clear result which showed that deterioration of the fish is linear and strong correlated with the time of storage $\left(\mathrm{R}^{2}=0.966\right)$. High correlation between total QI and storage time, quite close to this research, were previously reported for rainbow trout $\mathrm{R}^{2}=0.966$ (Erikson et al., 2017), $\mathrm{R}^{2}=0.992$ (Kolakowska et al, 2006) and farmed salmon $\mathrm{R}^{2}=0.969$ or $\mathrm{R}^{2}=0.953$ (Sveinsdotir et al., 2002, 2003). Whether or not a scheme is proper to use in fish freshness assessment like in this study or when a new scheme is developed for fish species, the scheme must be able to describe fish deterioration in linear correlation with storage time. The possibility to describe the fish postmortem changes (deterioration) in linear correlation with storage time is one of the most important reasons of using the QIM in quality assessment. This scheme characteristic allows the fast and easy way of calculating the time that fish were stored in ice and prediction of the remaining shelf life (Larsen et al, 1992; Hylding and Nielsen, 1997; Luten and Martinsdotir, 1997; Sveindsdotir et al., 2003). As it is shown from the results, the QIM scheme for the farmed Salmon (Figure 1) meets one of the main conditions to be used in fresh water rainbow trout freshness assessment. 
Table 1 Quality Index Method (QIM) scheme of farmed salmon used in this study to evaluate the rainbow trout freshness*

\begin{tabular}{|c|c|c|c|}
\hline Quality & Parameter & Description & Score \\
\hline \multirow{13}{*}{ Skin } & \multirow{4}{*}{ Colour/Appearance } & Pearl - shiny all over the skin & 0 \\
\hline & & The skin is less pearly - shiny & 1 \\
\hline & & The fish is yellowish, mainly near the abdomen & 2 \\
\hline & & Clear, not clotted & 0 \\
\hline & \multirow[t]{2}{*}{ Mucus } & Milky, clotted & 1 \\
\hline & & Yellow and clotted & 2 \\
\hline & \multirow{4}{*}{ Odour } & Fresh seaweed, neutral & 0 \\
\hline & & Cucumber, metal, hay & 1 \\
\hline & & Sour, dish cloth & 2 \\
\hline & & Rotten & 3 \\
\hline & \multirow{3}{*}{ Texture } & In rigor & 0 \\
\hline & & Finger mark disappears rapidly & 1 \\
\hline & & Finger leaves mark over 3 seconds & 2 \\
\hline \multirow{6}{*}{ Eyes } & \multirow{4}{*}{ Pupils } & Clear and black, metal shiny & 0 \\
\hline & & Dark, gray & 1 \\
\hline & & Matt, gray & 2 \\
\hline & & Convex & 0 \\
\hline & \multirow[t]{2}{*}{ Form } & Flat & 1 \\
\hline & & Sunken & 2 \\
\hline \multirow{10}{*}{ Gills } & \multirow{3}{*}{ Colour } & Red/ dark brown & 0 \\
\hline & & Pale red, pink/light brown & 1 \\
\hline & & Grey-brown, brown, grey, green & 2 \\
\hline & & Transparent & 0 \\
\hline & \multirow[t]{3}{*}{ Mucus } & Milky, clotted & 1 \\
\hline & & Brown clotted & 2 \\
\hline & & Fresh, seaweed & 0 \\
\hline & \multirow{3}{*}{ Odour } & Metal, cucumber & 1 \\
\hline & & Sour, mouldy & 2 \\
\hline & & Rotten & 3 \\
\hline \multirow{7}{*}{ Abdomen } & \multirow{2}{*}{ Blood in abdomen } & Blood red/not present & 0 \\
\hline & & Blood more brown, yellowish & 1 \\
\hline & \multirow{5}{*}{ Odour } & Neutral & 0 \\
\hline & & Cucumber, melon & 1 \\
\hline & & Sour, fermenting & 2 \\
\hline & & Rotten/ rotten cabbage & 3 \\
\hline & & Quality Index total score & $0-24$ \\
\hline
\end{tabular}

*The scheme (figure 1) was made according to "QIM EUROFISH" www.qim-eurofish.com

\section{Total QI score}

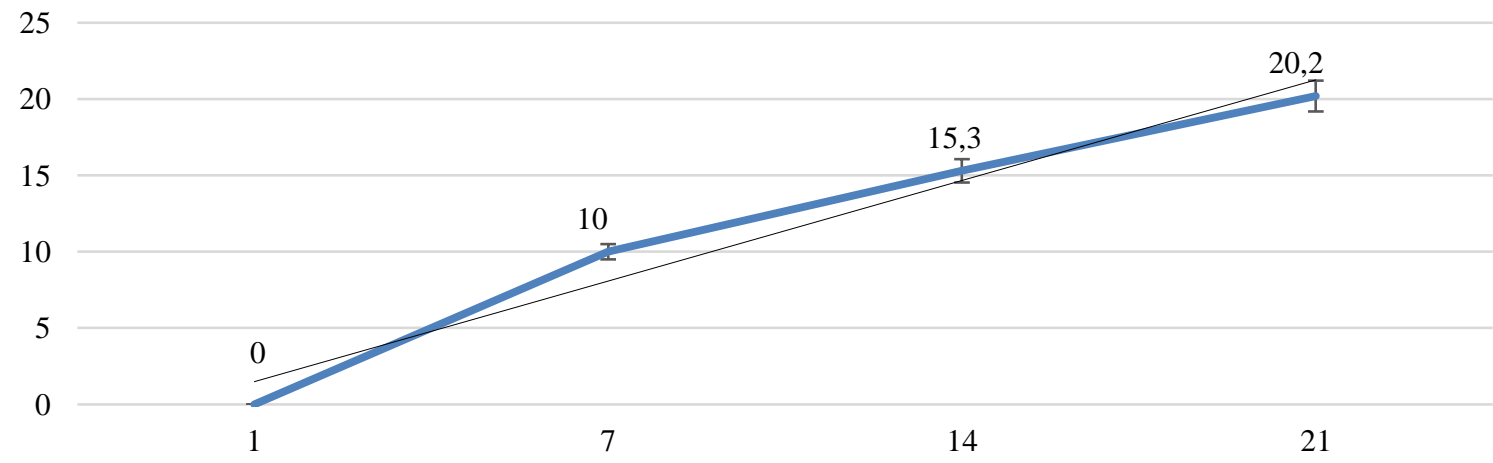

Figure 1 Average total QI score of fresh water Rainbow trout stored in ice, on day 1, 7, 14 and 21, assessed with QIM scheme for farmed salmon. (Vertically - QI score, horizontally - Days on ice) 
Regarding the shelf life of ice stored rainbow trout; most of the previous researches have reported a shelf life of 14 -16 days. In a study when a modified scheme for rainbow trout was used, a shelf life of $14-16$ days was estimated as rejection time (Wunnenberg and Oehlenschlag, 2008) which corresponded to the score of 14 -16 demerit points of the scheme. Based on microbiological, chemical and sensory assessment, approximately the same shelf life (14 days) was recommended for ice stored ungutted rainbow trout (Dawod et al., 1986, Kolakowska et al, 2006). All these results were quite similar to present study where the QI score of 15.3 was reached in day 14 (Figure 1).

Regarding some discrepancies among the results, it should be mentioned that the freshness assessment or storage time with QIM can be determined with an accuracy of \pm 2 day (Sveinsdottir et al., 2002).

If we consider the findings of the above-mentioned authors regarding the shelf life of ice stored fish and the fact that the QIM is in linear correlation with the storage time (Figure 1), the results of the sensory evaluation are confirmed and the rejection time for ice stored rainbow trout should be at 15 demerit points of the scheme or $14 \pm$ 2 days of ice storage.

Total quality score is a collection of the specific quality parameters score which are shown in Figure 2.

Skin colour after 7 days of storage was almost not affected and the fish seems to be fresh, whereas on day 14 the skin lost its shine and looked more fade toward the yellowish, mainly around the belly (Figure 2.1).
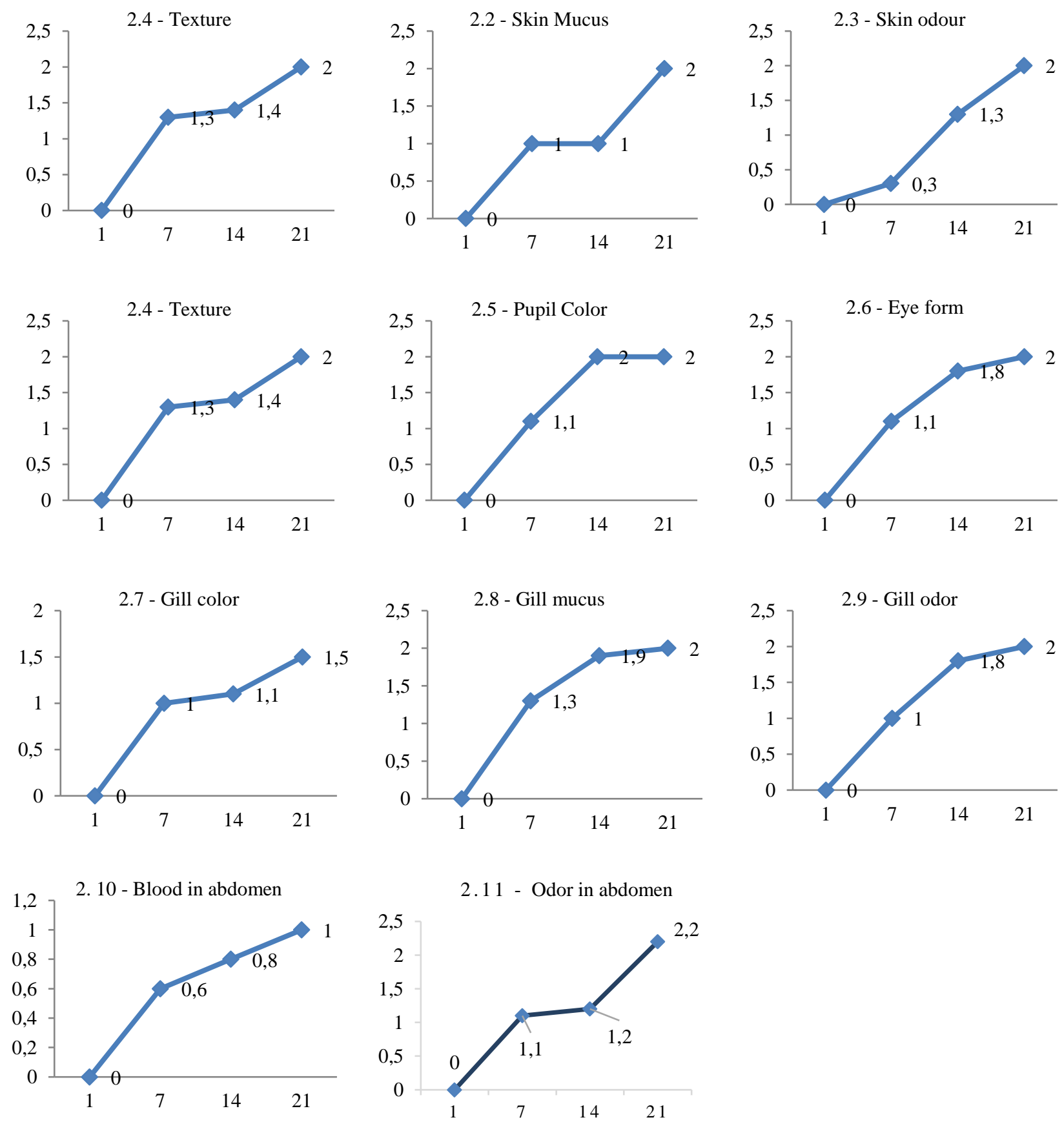

Figure 2 Average score of each quality attribute of fresh water Rainbow trout stored in ice, on day 1, 7, 14 and 21, assessed with QIM scheme for salmonides. (Vertically - QI score, horizontally - Days on ice) 
Gill colour was more affected than the skin colour by storage time ( $\mathrm{P}>0.05)$. The gills lost the colour of the fresh fish just after 7 days of storage (Figure 2.7).

Skin odour was neutral until the $14^{\text {th }}$ day of storage. Afterwards, a cucumber smell was detected. On day 21 the skin odour was sour. Rotten smell never was detected (Figure 2.3). Similar results were reported for farmed salmon, for a neutral odour between 8 and 15 and sour between 16 and 20 demerit points respectively, which correspondents to the same value on days (Hyldig and Green-Petersen, 2004). Gills odour, same as the color, deteriorates faster than skin odour $(\mathrm{P}>0.05)$. Gills had cucumber smell just after 7 days of storage, furthermore, some fish smelt sour at the same time (Figure 2.9).

Regarding the smell, the abdominal odour was the most affected attribute (Figure 2.11). This happens because the guts located in abdominal cavity are loaded with the bacteria, as result deterioration progresses faster. The odour as main cause of the fish quality loss was also described previously (Rezai and Hosein, 2008). In another study was reported that fish lose their characteristic fresh odour in the first days of storage, after that fish become odourless until the bed smell occurs as result of sulphur and nitrogen volatiles (Hylding et al., 2007).

However, only in one fish, on day 21 of ice storage, rotten smell of the abdominal cavity was detected. The rear detection of the rotten smell on fish stored in ice, also was reported for the farmed salmon (Sveindsdotir et al., 2002). Undesirable sour or rotten smell of the fish is as result of sulfur compounds, alcohols, amines and short chain acids produced by the bacterial activity (Ofalsdotir and Flerence, 1997).

Except the bacterial activity the deterioration of the fish also happens because of the enzyme activity.

The fish muscle enzymes and bacterial enzymes causes the softness of the fish texture (Gill, 1995; Nilsen, 1995). The softness of fish texture along the storage was detected in this study too (Figure 2.4).

Skin and gills mucus (Figure 2.2 and 2.8) got clotted on day 7 of ice storage. Skin mucus was on the same QI values on the $14^{\text {th }}$ day $(\mathrm{P}<0.05)$, even if the mucus on day 14 was milkier, it didn't change the colour.

The score for quality attributes of eye (pupils colour and form) increase constantly throughout the storage time $(\mathrm{P}>0.05)$ (Figure 2.5 and 2.6). Similar results were observed for the farmed salmon. (Sveindsdotir et al., 2003).

The blood in abdomen was present on day 7 and it looked brown. On day 14 and 21 a presence of the almost yellowish liquor was detected, and it is hard to say if that was blood. It looked more like a mix of blood, water and abdominal cavity liquors (Figure 2.10).

When the collected data were statistically analysed, differences were observed between all the assessment periods $(\mathrm{P}>0.05)$ except the skin mucus between days 1-14 and pupil colour after day 14 .

Regarding the skin mucus between days $7-14$, as was described above, this happens because the mucus didn't change the colour which would give the next score, even the mucus became milkier.

In the case of the pupil colour, it reaches the maximal value on day 14 .

As described above, all the sensory quality attributes changes that occurred during the ice storage time, were listed in the scheme with a very precise ranking which allows their description and score.

\section{Conclusions}

According to this research the QIM scheme for farmed salmon is proper to use in evaluation of the rainbow trout freshness. It describes very well the specific attributes and produced a linear correlation between QI total score and time of storage, it also can be used to ascertain and predict the remaining shelf life of ice stored rainbow trout. Regarding the shelf life, we propose a maximal shelf life of $14 \pm 2$ days for ungutted rainbow trout or 15 demerit points of framed salmon QIM scheme. However, this does not mean that a specific QIM scheme for rainbow trout is not needed, but until it is set up and accepted for use, QIM scheme for salmonids can be very well used.

\section{Acknowledgements}

This study was funded by the Ministry of Foreign Affairs (Norway) under the SEAMED (Strengthening Education, Applied Research, and Marine Development in West-Balkan) project - a part of 'Program in Higher Education, Research and Development in the Western Balkans 2010-2014, Maritime Sector (HERD Maritime)'. Without the kind support of the "Trofta" Istog Company in Kosovo, the present research would not be possible.

\section{References}

Bonilla AC, Sveinsdotir K, Martinsdottir E. 2007. Development of quality index method (QIM) scheme for fresh cod (Gadus morhua) fillets and application in shelf life study. Food Control, 18: 352-358.

Bremner AA. 1985. Convenient easy - to - use system for estimating the quality of chilled seafood. Proceedings of the fish processing conference. Nelson, New Zealand. Fish Processing Bulletin, 7: 59-73.

Dawood AA, Roy RN, Williams CS. 1986. Effect of delayed icing on the storage life of rainbow trout. Journal of Food Technology, 21: 159 - 166. DOI: 10.1111/j.13652621.1986.tb00437.x

Erikson E, Shabani F, Beli E, Rexhepi A. 2017. The impact of perimortem stress and gutting on quality index and color of rainbow trout (Oncorhynchus mykiss) during ice storage: A commercial case study. European Food Research and Technology, 244, 197 - 206. DOI: 10.1007/s00217-0172944-9

Gill T. 1995. Autolytic changes. In: Quality and quality changes in fresh fish: Hys, HH. 39-51 available at: https://www.worldcat.org/title/quality-and-quality-changesin-fresh-fish/oclc/33444169

Hylding G, Green-Petersen DMB. 2004. Quality index method an objective tool for determination of sensory quality. Journal of Aquatic Food Product Technology, 13, 71-80. DOI: 10.1300/J030v13n04_06

Hylding G, Nielsen JA. 1997. Rapid sensory method for quality management. In: Methods to determine the freshness of fish in research and industry. Olafsdottir G, Lutena J, Dalgard P, Careche M, Verrez-Bagnis V, Martinsdottir E. 297-305.

Hylding G, Bremner A, Martinsdottir E, Schelvis R. 2007. Quality index method. In: Handbook of meat, poultry and seafood quality. Nollet LML, Boylston T, Chen F. Oxford Blackwell 499-510.

Kolakowska A, Zienkowicz L, Domiszewski Z, Bienkiewicz G. 2006. Lipid changes and sensory quality of whole- and gutted rainbow trout during ice storage. Acta Ichthyologica et Piscatoria, 36: 39 - 47. DOI: 10.3750/AIP2006.36.1.06 
Larsen EP, Heldbo J, Jespersen CM, Nielsen J. 1992. Development of a standard for quality assessment on fish for human consumption. In: Quality assurance in the fish industry. Huss HH, Jacobsen M, Liston J. 351- 358.

Luten JB, Martinsdottir E. 1997. QIM: A European tool for fish freshness evaluation in the fishery chain. In: Methods to determine the freshness of fish in research and industry. Olafsdottir G, Lutena J, Delgard P, Careche M, VerrezBagnis V, Martinsdottir E, Heia K. 287 - 296.

Nilsen J. 1995. Sensory changes. In: Quality and quality changes in fresh fish: Hys HH. 35-39

Olafsdottir G, Fleurence J. 1997. Evaluation of fish freshness using volatile compounds-classification of volatile compounds in fish. Methods to determine the freshness of fish in research and industry. Proceedings of the final meeting of the concerted action "Evaluation of Fish Freshness", Nantes conference, 297-305.

Ozogul Y, Yuvka İ, Ucar Y, Durmus M, Kösker AR, Öz M, Ozogul F. 2017. Evaluation of effects of nanoemulsion based on herb essential oils (rosemary, laurel, thyme and sage) on sensory, chemical and microbiological quality of rainbow trout (Oncorhynchus mykiss) fillets during ice storage. $L W T$, 75, 677-684.

Öz M, Dikel S, Durmuş M, Özoğul Y. 2017. Effects of Black Cumin Oil (Nigella sativa) on Sensory, Chemical and Microbiological Properties of Rainbow Trout during 23 Days of Storage at $2 \pm 1$ C. Journal of Aquatic Food Product Technology, 26(6): 665-674.
Öz M. 2018. Effects of garlic (Allium sativum) supplemented fish diet on sensory, chemical and microbiological properties of rainbow trout during storage at- $18 \mathrm{C}$. LWT, 92, 155-160.

Rezaei M, Hosseini SF. 2008. Quality assessment of farmed rainbow trout (Oncorhynchus mykiss) during chilled storage. Journal of Food Sciences, 73, H93-H96. DOI: 10.1111/j.1750-3841.2008.00792.x

Sveinsdottir K, Martinsdottir E, Hylding G, Jørgensen B, Kristbergsson K. 2002. Application of quality index method (QIM) scheme in shelf-life study of farmed Atlantic salmon (Salmo salar). Journal of Food Sciences, 67: 1570-1579. doi.org/10.1111/j.1365-2621.2002.tb10324.x

Sveinsdottir K, Hylding G, Martinsdottir E, Jorgensen B, Kristbergson K. 2003. Quality index method (QIM) scheme developed for farmed Atlantic salmon (Salmo salar). Food Quality and Preference, 14, 237-245. DOI: 10.1016/S09503293(02)00081-2

Vaz-Pirez P, Seixas P. 2006. Development of new quality index method (QIM) for cutlet fish (Sepia officinalis) and broadtail shortfish squid (Illex coindenti). Food Control, 17, 942-949. DOI: 10.1016/j.foodcont.2005.07.004

Wunnenberg J, Oelhenschlager A. 2008. Investigation on shelf life of ice stored aquacultured rainbow trout (Oncorhynchus mykiss) in relation to annual seasonal factors by application of the Quality index iethod (QIM) for gutted whole fish and sensory assessment for cooked fillets. $\mathrm{PhD}$ dissertation. Lebensmittelhyg Germany. 